\title{
Numerical Simulation of Wind Field Characteristics around Two Adjacent High-Rise Buildings
}

\author{
Wenkai He, Weibin Yuan* \\ College of Civil Engineering, Zhejiang University of Technology, Hangzhou, China \\ Email:
}

Received January 2014

\begin{abstract}
This paper based on Reynolds-averaged Navier-Stokes equations standard $k-\varepsilon$ model [1]; the surface pressure on the wind field around two adjacent high-rise buildings was numerically simulated with software Fluent. The results show that with the influence of adjacent high-rise building, numerical simulation is a good way to study the wind field around high-rise building and the distribution of wind pressure on building' surface. The pressures on the windward surface are positive with the maximum at $2 / 3 \mathrm{H}$ height and have lower values on the top and bottom. The pressures on the leeward surface and two sides were negative. Due to the serious flow separation at the corner of building's windward, the wind field has a high turbulent kinetic energy.
\end{abstract}

\section{Keywords}

High-Rise Building, Numerical Simulation, Wind Field Characteristics, Turbulence Model

\section{Introduction}

Studies on a square or a rectangular cross-section building affected by wind have been made by many researchers owing to its importance. However, a single building is a very rare case in the real world [2]-[4]. Shuyong Tang and Shuifu Chen [5] suggested that building's wind pressure and surrounding wind field will be affected by the adjacent building. And when it comes to high-rise building, the influence will be even more serious if there is another high-rise building beside it.

Nowadays having studied of wind field characteristic on high-rise building we can use both wind tunnel test and numerical simulation. The wind tunnel test has been widely used to determine the aerodynamic characteristics of buildings for years [6]-[8]. However, wind tunnel test requires strict conditions of similarity, and it is also difficult to simulate both atmospheric boundary layer turbulence structure features and inlet wind velocity profile. What's more, the test conditions have to change in order to adjust to different wind and building environment. Comparing with the wind tunnel test, numerical simulation has the characteristics of low cost, short cycle and high efficiency. It can be conveniently by changing various parameters to simulate the flow field characteristics of various kinds of ideal and real conditions. This paper would like to study the wind field characteristics by using the numerical simulation.

*Corresponding author. 


\section{Numerical Simulation}

\subsection{Governing Equations}

The governing equation of incompressible turbulent wind flow around building is presented by the Reynoldsaveraged Navier-Stokes equations [1] as follows:

$$
\begin{gathered}
\frac{\partial u_{i}}{\partial x_{i}}=0 \\
\frac{\partial u_{i}}{\partial t}+u_{j} \frac{\partial u_{i}}{\partial x_{j}}=-\frac{1}{p} \frac{\partial p}{\partial x_{i}}+\frac{\partial}{\partial x_{j}}\left[\eta\left(\frac{\partial u_{i}}{\partial x_{j}}+\frac{\partial u_{j}}{\partial x_{i}}\right)-\overline{u_{i}^{\prime} u_{j}^{\prime}}\right]
\end{gathered}
$$

where $\eta=\mu / \rho$ is Kinematic viscosity.

The standard $k-\varepsilon$ model of the turbulent kinetic energy and turbulent kinetic energy dissipation for the transport equation of the closed form is:

$$
\begin{gathered}
\frac{\partial k}{\partial t}+u_{j} \frac{\partial k}{\partial x_{j}}=\eta_{t} \frac{\partial u_{i}}{\partial x_{j}}\left(\frac{\partial u_{i}}{\partial x_{j}}+\frac{\partial u_{j}}{\partial x_{i}}\right)-\frac{\partial}{\partial x_{j}}\left[\left(\eta+\frac{\eta_{t}}{\sigma_{k}}\right) \frac{\partial k}{\partial x_{j}}\right]-\varepsilon \\
\frac{\partial \varepsilon}{\partial t}+u_{j} \frac{\partial \varepsilon}{\partial x_{j}}=\frac{C_{1} \varepsilon}{k} \eta_{t} \frac{\partial u_{i}}{\partial x_{j}}\left(\frac{\partial u i}{\partial x_{j}}+\frac{\partial u_{j}}{\partial x_{i}}\right)-\frac{\partial}{\partial x_{j}}\left[\left(\eta+\frac{\eta_{t}}{\sigma_{\varepsilon}}\right) \frac{\partial \varepsilon}{\partial x_{j}}\right]-C_{2} \frac{\varepsilon^{2}}{k}
\end{gathered}
$$

where turbulent kinetic energy is $k=\frac{1}{2} u_{i} u_{i}$; Turbulent kinetic energy dissipation is $\varepsilon=\eta \frac{\partial u_{i}}{\partial x_{j}} \frac{\partial u_{i}}{\partial x_{j}}$; Turbulent kinematic viscosity coefficient is $\eta_{t}=C_{\mu} \frac{k^{2}}{\varepsilon}$.

The coefficients of standard $k-\varepsilon$ model are in Table 1 .

\subsection{Model and Working Condition}

This paper's study objects are two adjacent high-rise buildings, its length, width and height are $40 \mathrm{~m}, 40 \mathrm{~m}$ and $120 \mathrm{~m}$, respectively and are 60 meters apart. Geomorphic types are class $\mathrm{C}$. The buildings are rules, but the influence effect between two buildings makes it hard to predict the wind field around two buildings. In order to study the wind field characteristics of two adjacent high-rise buildings, considering symmetry, we only choose $0^{\circ}$ and $90^{\circ}$ two different wind angles as working conditions.

\subsection{Computational Domain and Boundary Conditions}

\subsubsection{Computational Domain}

The upper boundary is $3 \mathrm{H}$, and the inflow boundaries extend $3 \mathrm{H}$ upstream of the windward face and outflow boundaries reach $5 \mathrm{H}$ downstream of the leeward face ( $\mathrm{H}$ is the building height, value $120 \mathrm{~m}$ ). The domain width is $2 \mathrm{H}$ from the sideward face. And the setting of flow field meets the requirement of blocking rate that should be less than $3 \%$. Considering the calculation efficiency, all of the grids we using are unstructured, which are meshed by software CFD.

\subsubsection{Boundary Condition}

Although the wind flow around building is totally an open flow wind field, when using numerical simulation, we should have a bounded 3D computational domain, calculation area and the building wall boundary condition [5]. The entrance to the boundary of the atmospheric boundary layer wind speed profile we usually use speed inlet conditions, and its average velocity distribution is

Table 1. Coefficients of standard $k-\varepsilon$ model.

\begin{tabular}{ccccc}
\hline$C_{\mu}$ & $\sigma_{k}$ & $\sigma_{\varepsilon}$ & $C_{1}$ & $C_{2}$ \\
\hline 0.09 & 1.0 & 1.3 & 1.44 & 1.92 \\
\hline
\end{tabular}




$$
\frac{\bar{v}(z)}{\overline{v_{b}}}=\left(\frac{z}{z_{b}}\right)^{\partial}
$$

where $z_{b}, \overline{v_{b}}$ are Standard reference height and the average speed of Standard reference height, respectively; $z, \bar{v}(z)$ mean height and the speed value in the height; $\partial$ is the ground roughness index.

According to the load code for design of building structure [9], the basic wind pressure encounters every 50 years in Hangzhou Zhejiang province is $0.4 \mathrm{kN} / \mathrm{m}^{2}$. Based on equation

$$
P=\frac{1}{2} \rho v^{2}
$$

we can get the basic wind speed is $24.9 \mathrm{~m} / \mathrm{s}$. And the building landscape types is class $\mathrm{C}$, its ground roughness index values 0.22 . Outlet boundary using pressure outlet boundary conditions, the outlet pressure is $0 \mathrm{~Pa}$. Watershed top and sides adopt symmetrical boundary condition. Building surface and ground with no slip wall condition.

\subsection{Convergence Criteria}

Calculation to the parameters relative to iterative residual are less than $1 \times 10^{-5}$, and observe the building surface wind pressure coefficient of basic don't change, then we can say that the calculation of flow field simulation is stable.

\section{Results and Discussion}

\subsection{Numerical Pressure Coefficients}

Wind pressure coefficient is defined as the reference height building surface static pressure to the distance of measuring points to flow static pressure ratio:

$$
\mu_{\mathrm{si}}=\frac{\mathrm{w}_{\mathrm{i}}}{\frac{1}{2} \rho \overline{\mathrm{v}}^{-2}}
$$

where $\mu_{\mathrm{si}}$ is the average wind pressure coefficient of measuring point $\mathrm{i} ; \mathrm{w}_{\mathrm{i}}$ is the net wind pressure of measuring point $\mathrm{i} ; \overline{\mathrm{v}}$ is the average wind speed of reference height; $\rho$ is the air density, $1.225 \mathrm{~kg} / \mathrm{m}^{3}$.

Figure 1 is the overall building surface wind pressure coefficient contour map at the wind angle $0^{\circ}$ and $90^{\circ}$, respectively.

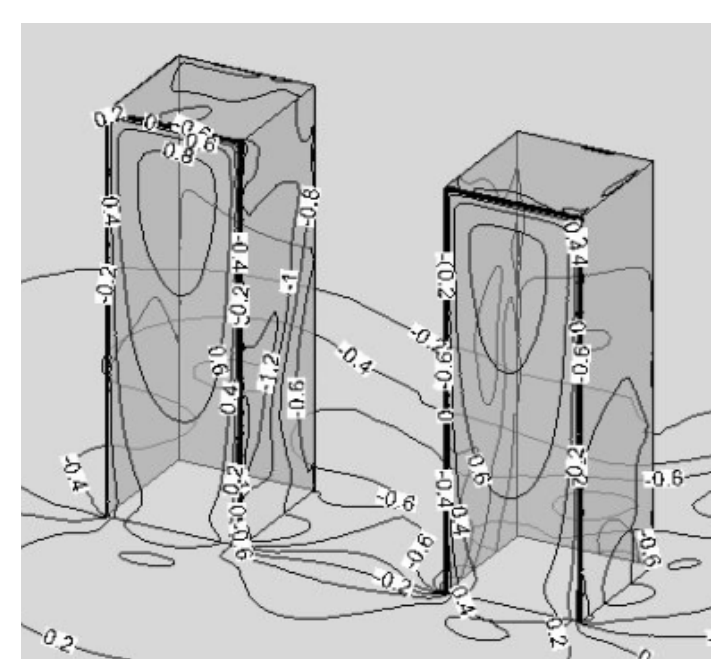

(a)

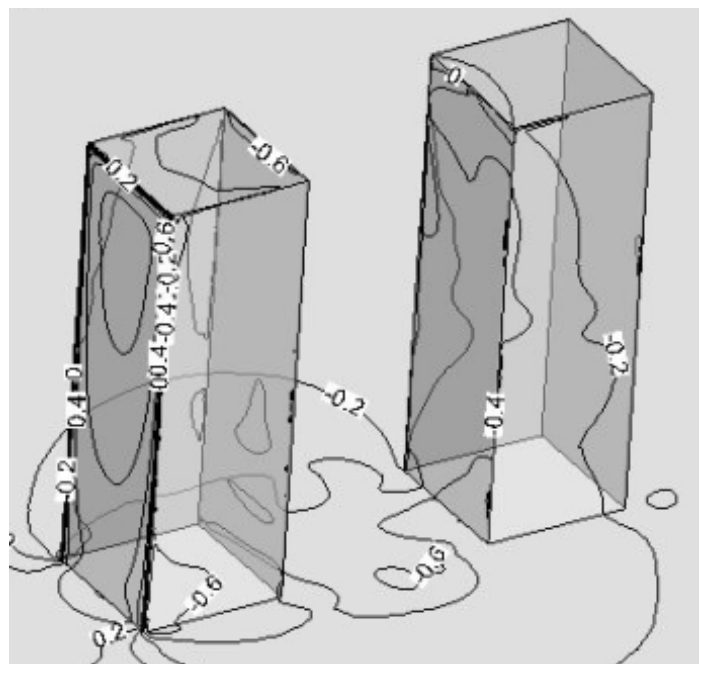

(b)

Figure 1. Overall building surface wind pressure coefficients contour map, (a) $0^{\circ}$; (b) $90^{\circ}$. 
From Figure 1 we can see that at the wind angle of $0^{\circ}$, the pressure coefficients on the windward surface are positive with the maximum at $2 / 3 \mathrm{H}$ height and have lower values on the top and bottom. In a word, the pressure coefficients in the middle are larger than that on the top and bottom. And the negative pressures on the channel wall are larger than that on the other wall.

At the wind angle of $90^{\circ}$, building on the upstream, its pressure coefficients on the windward surface are positive. And the circular contour on its leeward surface suggests that the flow field in the vortex structures. Building on the downstream is in the wake stream of building on the upstream, pressures on its surface are negative, and the pressure coefficients are irregular.

Form Figure 2 we can see that the pressure coefficients with the maximum at $95 \mathrm{~m}$, which is about $2 / 3 \mathrm{H}$ high. And the pressure coefficients with the minimum at the channel between two buildings, which suggests that wall in the channel with the largest negative pressures. Pressures on leeward and sideward are also negative.

\subsection{Distribution of Turbulent Kinetic Energy}

The turbulent kinetic energy means the level of fluid pulsation.

From Figure 3 we can see that the turbulence kinetic energy mainly on the windward and channel wall, which suggests that in these places flow separation is serious.

\subsection{Velocity Distribution and Flow Field Analysis}

From Figure 4 we can see that flow field on the leeward forms a circular contour, likes a big whirlpool, so as to cause the suction. Flow field on the sideward forms the separation zone. At the wind angle of $90^{\circ}$, building on the downstream is in the wake stream of building on the upstream, the velocity is negative.

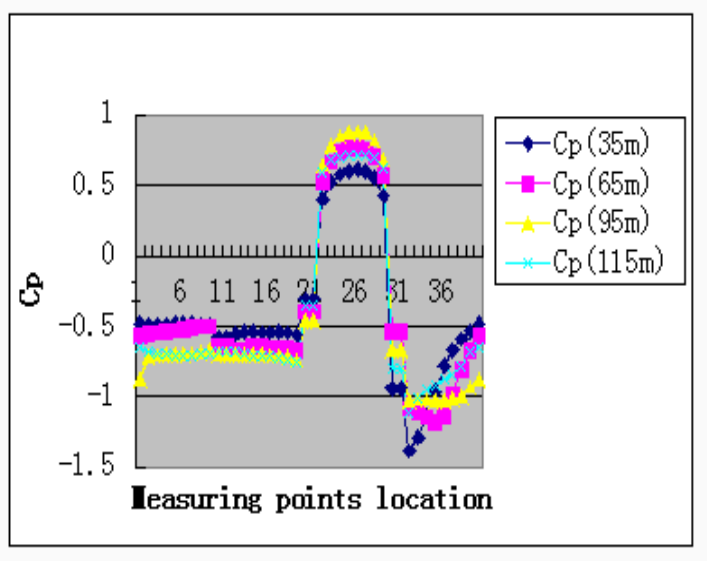

(a)

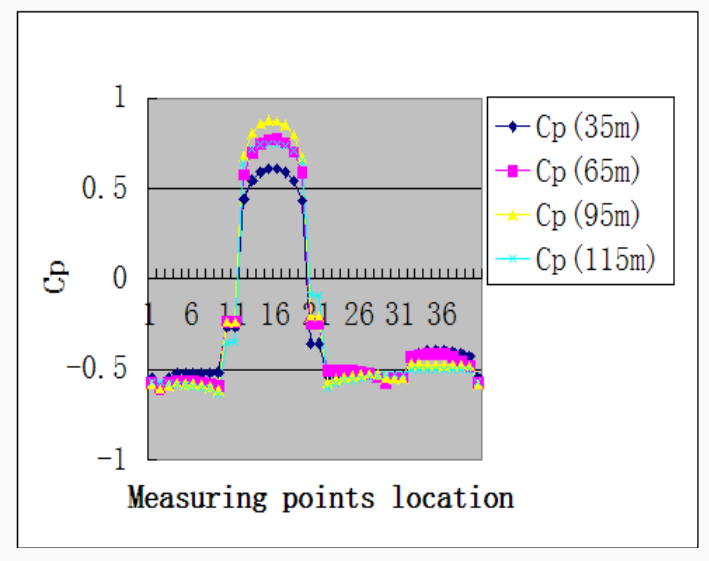

(b)

Figure 2. Pressure coefficients at the height of $35 \mathrm{~m}, 65 \mathrm{~m}, 95 \mathrm{~m}$ and $115 \mathrm{~m}$, (a) $0^{\circ}$; (b) $90^{\circ}$.

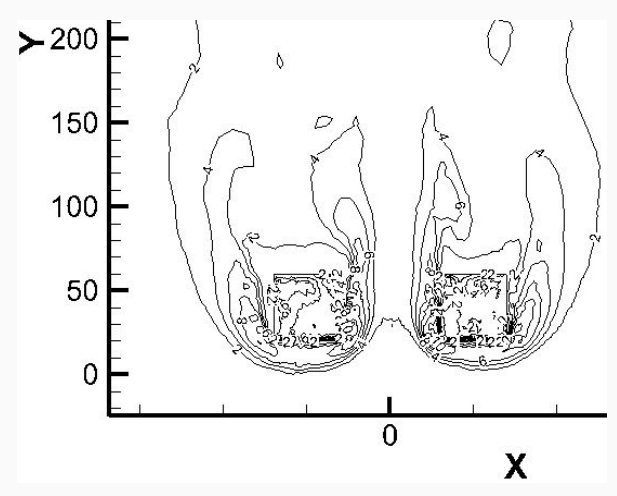

(a)

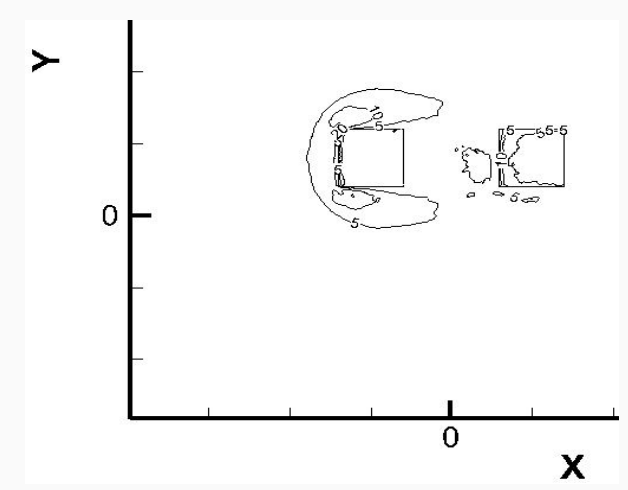

(b)

Figure 3. Turbulence kinetic energy contour map, (a) $0^{\circ}$; (b) $90^{\circ}$. 


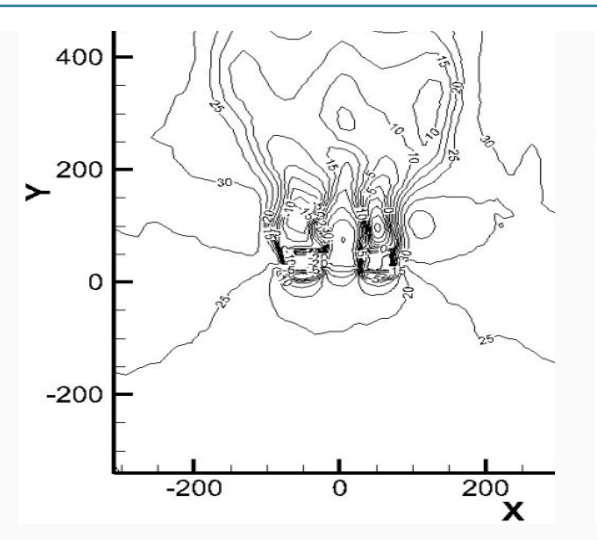

(a)

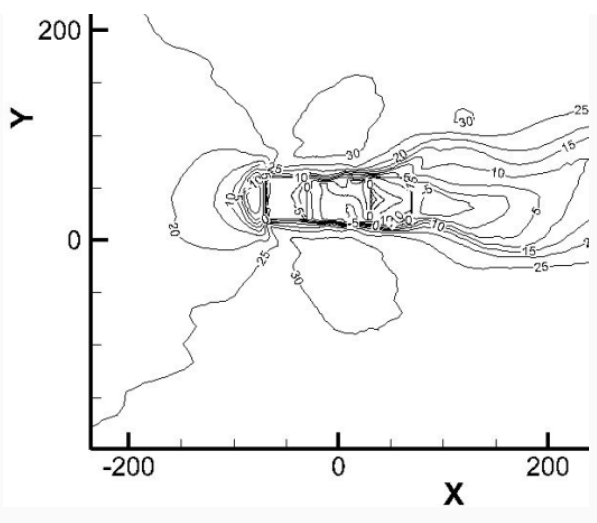

(b)

Figure 4. Velocity distribution contour map, (a) $0^{\circ}$; (b) $90^{\circ}$.

\section{Conclusions}

Numerical simulation is a good way to study the wind field around high-rise building and the distribution of wind pressure on building's surface. The pressure coefficients in the middle are larger than that on the top and bottom, and with maximum at the height of $2 / 3 \mathrm{H}$. Pressures on leeward and sideward are negative.

Due to the influence of adjacent building, wall in the channel with the minimum negative pressures which suggest that the channel effect is serious. And the turbulence kinetic energy in the channel has a high level. At the wind angle of $90^{\circ}$, building on the downstream is in the wake stream of building on the upstream, the velocity is negative.

\section{References}

[1] Yakhot, V., et al. (1992) Development of Turbulence Models for Shear Flows by a Double Expansion Technique. Physics of Fluids A, 4, 1510-1520.

[2] Okajima, A. (1982) Strouhal Number of Rectangular Cylinders. Journal of Fluid Mechanics, 123, 379-398. http://dx.doi.org/10.1017/S0022112082003115

[3] Kwok, K.C.S. (1983) Effects of Turbulence on the Pressure Distribution around a Square Cylinder and Possibility of Reduction. Trans. ASME: Journal of Fluids Engineering, 105, 140-145.

[4] Courchesne, J. and Laneville, A. (1982) An Experimental Evaluation of Drag Coefficient for Rectangular Cylinders Exposed to Grid Turbulence. Trans. ASME: Journal of Fluids Engineering, 104, 523-527.

[5] Yong, T.S., CHen, S.F. and Tang, J.C. (2004) Numerical Simulation of Wind Pressure on Adjacent Tall Building. Chinese Journal of Computational Mechanics, 21, 159-160.

[6] Xie, Z.N. and Gu, M. (2004) Mean Interference Effects among Tall Buildings. Engineering Structures, 26, $1173-1183$. http://dx.doi.org/10.1016/j.engstruct.2004.03.007

[7] Xie, N.X. and Gu, M. (2005) A Correlation-Based Analysis on Wind-Induced Interference Effects between Two Tall Buildings. Wind and Structures, 8, 163-178. http://dx.doi.org/10.12989/was.2005.8.3.163

[8] Xie, Z.N. and Gu, M. (2007) Simplified Evaluation of Wind-Induced Interference Effects among Three Tall Buildings. Journal of Wind Engineering \& Industrial Aerodynamics, 95, 31-52. http://dx.doi.org/10.1016/j.jweia.2006.05.003

[9] Load Code for Design of Building Structure. 